\title{
Psychopharmacology of Aggression in Children and Adolescents with Autism: A Critical Review of Efficacy and Tolerability
}

\author{
Mihir S. Parikh, B.Sc., ${ }^{1}$ Alexander Kolevzon, M.D., ${ }^{2,3}$ and Eric Hollander, M.D. ${ }^{2,3}$
}

\begin{abstract}
Background: Autism is characterized by a clinical triad of symptoms that affect social, language, and behavioral domains. Aggression and self-injury may be associated symptoms of autism and can result in significant harm to those affected as well as marked distress for their families. The precise nature of the relationship between aggressive or self-injurious behavior (SIB) and autism remains unclear and as a result, these symptoms are treated with a broad range of pharmacological approaches. This review seeks to systematically and critically examine the evidence for the pharmacological management of aggression and SIB in children with autism spectrum disorders.

Method: The entire PubMed database was searched for English language biomedical articles on clinical trials with medication in autism spectrum disorders. Studies were selected based on the following inclusion criteria: (1) randomized placebo-controlled trials; (2) a sample population that included children and adolescents; (3) at least one standardized assessment of aggression as a primary outcome measure of the study.

Results: Twenty one trials with 12 medications were identified. Five medications produced significant improvement as compared to placebo, including tianeptine, methylphenidate, risperidone, clonidine, and naltrexone. Only risperidone and methylphenidate demonstrate results that have been replicated across at least two studies.

Conclusions: Although many medications have been studied under placebo-controlled conditions, few produce significant improvement. Additional placebo-controlled trials are needed to increase the number of therapeutic options available in the treatment of aggression in autism.
\end{abstract}

${ }^{1}$ Mount Sinai School of Medicine, New York, New York.

${ }^{2}$ Department of Psychiatry, Mount Sinai School of Medicine, New York, New York.

${ }^{3}$ Seaver Autism Research Center, Mount Sinai School of Medicine, New York, New York. 


\section{INTRODUCTION}

A UTISM IS A DEBILITATING NEURODEVELOPMENTAL DISORDER characterized by impairments in social, language, and behavioral domains. Yet, limited pharmacological options exist to treat either core symptom domains or associated psychopathology reliably. Aggression and self-injurious behavior (SIB) are among the manifestations of behavioral impairment in autism and are often the cause for emergent psychiatric referral. When present, aggression and SIB may be both dangerous and distressing for affected children and their families. Many medications have been studied in an effort to identify safe and efficacious interventions in children with autism. A number of reviews have been published that interpret and synthesize the current findings (King 2000; Barnard et al. 2002; Hollander et al. 2003a; McDougle et al. 2003; Aman 2004; Rappaport and Thomas 2004; Findling 2005; Malone et al. 2005; Kolevzon et al. 2006). Beyond harm reduction, the effective pharmacological management of associated symptoms may also improve response rates to behavioral and educational interventions in autism (Audenaert et al. 2001; McDougle et al. 2003; Findling 2005; Malone et al. 2005). Issues revolving around medication tolerability also warrant careful consideration in this vulnerable, developmentally disabled population (Harris 1996; Hollander et al. 2003a). The prevalence and impact of aggression and SIB in autism particularly warrants the need for a systematic review of medication efficacy and tolerability for these symptoms. Given the dearth of available pharmacological treatment in autism, and in light of recent controversy surrounding the use of medication in children and adolescents, the following review will critically examine all randomized controlled clinical trials (RCTs) that have examined the treatment of aggression and SIB in children and adolescents with autism and autism spectrum disorders.

The etiology of aggression and SIB remains unclear and is likely heterogeneous in nature (Rothenberger 1993; King 2000; Rappaport and Thomas 2004; Findling 2005). However, various mechanisms have been proposed to underlie the presence of these symptoms in autism, and numerous targets for pharmacological intervention have been suggested. These targets include the dopaminergic, serotonergic, adrenergic, and opioid systems, among others. Due to the diversity of hypothesized targets, the following section will review these mechanisms in further detail.

Several studies support an association between the dopaminergic system and aggression (Ferrari et al. 2003; Retz et al. 2003; Hoglund et al. 2005). Most animal models of self-injury suggest dysregulation of dopamine activity or dopamine receptor hypersensitivity as etiological factors (Rothenberger 1993). Dopamine dysregulation has also been implicated in self-injurious patients with autism (Shea et al. 2004), Lesch-Nyhan (Stodgell et al. 1998), and Tourette syndrome (Sandyk and Bamford 1987). This association has galvanized clinical trials with antipsychotic medications, most of which act as dopaminergic antagonists and may prevent the onset and maintenance of aggression and SIB (King 2000). In fact, the second-generation antipsychotic medication risperidone is the only agent specifically approved by the U.S. Food and Drug Administration (FDA) for the treatment of irritability, including aggression and self-injury, in children with autism (Food and Drug Administration 2006). Psychostimulant medications, on the other hand, are potent dopaminergic agonists and have also been examined in the treatment of aggressive children with autism. This apparent discrepancy between the use of both dopaminergic agonists and antagonists in the treatment of aggressive behavior in children with autism has not yet been fully reconciled. However, stimulant medications increase the availability of dopamine in the striatum, likely enhancing prefrontal cortical function though striatal-frontal pathways (Berridge et al. 2006) and improving inhibitory control. Antipsychotic medications, on the other hand, block dopamine receptor binding in the mesolimbic system (Stockton and Rasmussen 1996). Both classes of medications, despite differing mechanisms of action, may produce a final common effect in reducing aggression and impulsivity.

Central nervous system regulation of serotonin has also been implicated in aggressive behavior, and several studies have established an 
association between serotonin depletion and aggression in both human (Halperin et al. 2006) and animal models (Vergnes et al. 1988; Johansson et al. 1999). Work that specifically examines the association between serotonergic regulation and autism dates back to 1961, when Schain and Freedman (1961) first reported elevated levels of whole-blood serotonin in a subgroup of individuals with autism. Since then, most investigators have found that peripheral serotonin levels are significantly higher in subjects with autism as compared to normal controls (Ritvo et al. 1970; Takahashi et al. 1976; Anderson et al. 1987; Cook et al. 1990; Leventhal et al. 1990; Leboyer et al. 1999), and approximately one third of individuals with autism are considered to have hyperserotonemia (Hanley et al. 1977). In addition, worsening of autistic symptomatology has been demonstrated following acute depletion of dietary tryptophan (McDougle et al. 1996a). Selective serotonin reuptake inhibitors (SSRIs) are known to impact levels of peripheral and central serotonin, and if serotonin regulation is impaired in autism, it is possible that serotonergic medications may affect the dysregulation and ameliorate associated symptoms such as aggression and self-injury.

The adrenergic system has been proposed to play an etiological role in aggression. Individuals with autism have been observed to experience hyperarousal in response to ambient stimuli (Toichi and Kamio 2003), and it is possible that children with autism may engage in SIB in an effort to reduce environmental stimulation (King 2000). Therefore, adrenergic antagonists are a logical option for treatment because they block sympathetic discharge and diminish the hyperaroused state. $\alpha 2$-Adrenergic agonists have been suggested as candidates for pharmacotherapy because they lower production and plasma levels of catecholamines (Brede et al. 2003; Ihalainen and Tanila 2004). Clonidine, for example, has been shown to reduce tics in children with Tourette syndrome (Leckman et al. 1991) and to improve inattention, hyperactivity, and impulsivity in children with attention-deficit/hyperactivity disorder (ADHD) (Steingard et al. 1993; Connor et al. 1999; Hazell and Stuart 2003). Hyperactivity and impulsivity may appear in the context of autism, and as with ADHD, may also be accompanied by aggressive behavior. Therefore, clonidine has been suggested as a treatment option for aggression and other associated symptoms of autism.

There is evidence that the endogenous opioid system may also be critical to the maintenance of aggressive behavior, particularly selfdirected aggression (Sandman et al. 1997), and a relationship may exist between abnormalities in the endogenous opioid system and SIB in autism (Sandman 1988; Sandman et al. 2000). Several studies have demonstrated elevated plasma levels of $\beta$-endorphin in some children and adolescents with autism (Sandman 1988; Ernst et al. 1993; Bouvard et al. 1995; Cazzullo et al. 1999; Leboyer et al. 1999). One hypothesis posits that individuals who exhibit SIB become endorphin dependent, and chronic elevation of $\beta$-endorphin levels leads to downregulation of opioid receptors (Sandman 1988). In these patients, SIB is maintained by the need to release endogenous opiates to attenuate pain. Another hypothesis suggests that chronically elevated $\beta$-endorphins increase the pain threshold, resulting in reduced responsiveness to normal stimulation (Sandman 1988; Rothenberger 1993). Within this pain paradigm, patients initiate SIB to maintain adequate sensory stimulation. This theoretical evidence has bolstered several trials with naltrexone in subjects with autism. Naltrexone is a long-acting opiate antagonist that has been observed to decrease plasma $\beta$-endorphin levels in some individuals with autism (Bouvard et al. 1995; Cazzullo et al. 1999).

Valproate is an anticonvulsant and mood stabilizer that is primarily used in the treatment of seizure disorders, bipolar disorder, and migraine headaches. One proposed mechanism of action is its effect on the function of the neurotransmitter $\gamma$-aminobutyric acid (GABA) (Czapinski et al. 2005). Several observations have triggered studies of valproate for the treatment of aggression and self-injury in children with autism, including the presence of seizure disorders in approximately one third of individuals with autism (Danielsson et al. 2005) and evidence of antiaggressive properties of valproate in animal and human models (Molina et al. 1986; Hollander et al. 2003b; Sival 
et al. 2004; Hollander et al. 2005b, Gobbi et al. 2006). The high incidence of epilepsy in autism may also suggest a relationship with the phenomenon of kindling. Kindling refers to an experimental model of epilepsy where repeated application of subthreshold electrical stimulation to the brain leads to the progressive development of spontaneous seizures. Thus, it is possible to hypothesize a role for anticonvulsants in autism by treating subclinical epilepsy and possibly affecting intracellular processes involved in kindling-like models that may also be important for related symptoms of irritability and aggression (Soderpalm 2002). Lamotrigine is also an anticonvulsant and mood stabilizer that is primarily used in the treatment of seizure disorders and bipolar disorder. Levetiracetam is a novel anticonvulsant medication that is indicated as adjunctive therapy in the treatment of partial-onset seizures and primary generalized tonic-clonic seizures in adults and children. (Physicians' Desk Reference 2006). Along with valproate, lamotrigine and levetiracetam have also been studied as a potential tool to reduce aggressive behavior in children with autism.

Secretin is an endogenous gastrointestinal polypeptide that is produced in the cells of the duodenum. An important hormone of the digestive system, secretin regulates $\mathrm{pH}$ levels in the small intestine by reducing acid secretion in the stomach and by triggering the release of buffering fluids from the pancreas, liver, and duodenum (Imamura et al. 1993). Secretin has been suggested as a potential pharmacotherapy for autism for several reasons. First, children with autism appear to suffer from elevated rates of gastrointestinal problems (Horvath and Perman 2002). Second, researchers have proposed that secretin may impact central nervous system function through some as yet undetermined link between secretin receptors in the gastrointestinal system and certain regions of the developing brain (Horvath and Perman 2002). Finally, Horvath et al. (Horvath et al. 1998) reported marked improvements in several social and language parameters in a series of individuals with autism after treatment of gastrointestinal disorders with secretin. This finding received considerable media attention, and a significant number of placebo-controlled clinical trials subsequently sought to assess the efficacy of secretin in the treatment of autistic symptom domains.

Omega-3 long-chain-polyunsaturated fatty acids (LC-PUFA), such as docosahexaenoic acid (DHA) and eicosapentaenoic acid (EPA), are critical to normal brain development and function. However, these essential nutrients, found naturally in fish and fish oil, are often lacking in the diets of those living in developed countries. Recently, reports have implicated deficiencies or imbalances in these nutrients in the development of dyslexia (Baker 1985; MacDonell et al. 2000), ADHD (Mitchell et al. 1987; Stevens et al. 1995; Bekaroglu et al. 1996; Stevens et al. 1996; Burgess et al. 2000), and autism spectrum disorders (Bell et al. 2000; Vancassel et al. 2001; Bell et al. 2004). Conversely, supplementation of fish oils rich in omega-3 LC-PUFA in children with autism has reportedly led to improvements in general health, sleeping patterns, and social behavior (Bell et al. 2004). These observations have led to clinical trials with these nutrients to examine their efficacy in reducing aggression in children with autism. It is important to note that secretin and omega-3 fatty acids are more likely to be considered novel therapies and the rationales for their use in the treatment of aggression in individuals with autism are not as clearly defined as for most of the other medications included in this review.

To our knowledge, no recent review systematically evaluates the state of current evidence on pharmacotherapy specifically for aggression and SIB in children with autism. Previous reviews have examined the efficacy of medications in targeting a wide range of symptoms in autism; most have included results from uncontrolled case reports and open-label trials, and few have highlighted the methodological limitations of the studies presented (Rothenberger 1993; King 2000; Hollander et al. 2003a; McDougle et al. 2003; Aman 2004, Malone et al. 2005). We focus this review on studies in children and adolescents because of the unique characteristics of this population and likely developmental differences in both medication response and tolerability in autism (McDougle et al. 2003). We have chosen to select only RCTs for review in an effort to focus on studies that 
employ the most rigorous of scientific methodology. Although case reports and open-label studies make meaningful contributions to the literature, RCTs remain the gold standard for evaluating efficacy in clinical trials. On the basis of the results of this review, we also endeavor to draw evidence-based conclusions and to suggest directions for future research.

\section{METHODS}

Relevant studies were identified by: (1) searching the PubMed database for Englishlanguage biomedical articles on clinical trials of medication in the treatment of autism and autism spectrum disorders, and (2) screening reference lists of original studies. PubMed is a service of the National Library of Medicine that includes over 15 million citations from MedLine and additional life science journals that date back to the 1950s. For inclusion in this review, identified studies were required to meet the following a priori criteria: (1) a randomized controlled trial of agent versus placebo or active agent; (2) a well-defined sample of subjects that included children and adolescents with autism or autism spectrum disorders; (3) the use of at least one primary outcome measure with a standardized assessment of aggression and self-injury. Case reports, case series, and open-label trials were excluded from this review.

\section{RESULTS}

Twenty one randomized controlled trials were selected for inclusion in this review according to the criteria defined above. Results are presented in Table 1. These trials examined the efficacy and tolerability of the following medications: risperidone, haloperidol, clomipramine, methylphenidate, tianeptine, clonidine, naltrexone, secretin, omega-3 fatty acids, valproate, lamotrigine, and levetiracetam.

\section{Risperidone}

Three RCTs utilized a standardized outcome measure of aggression to examine the efficacy of risperidone, a combined dopamine and sero- tonin antagonist, in children with autism. In 2002, the Research Units on Pediatric Psychopharmacology (RUPP) Autism Network first published results from a large, multicenter trial (RUPP 2002). This first phase of the study began as a double-blind, placebo-controlled, parallel-group trial in 101 children and adolescents with autism over 8 weeks. Subjects ranged in age from 5 to 17 years $($ mean $=8.8)$. Risperidone was administered at a mean dose of $1.8 \mathrm{mg} /$ day for 8 weeks. The Aberrant Behavior Checklist-Irritability (ABC-I) subscale was the primary outcome measure of aggression and self-injury. Risperidone demonstrated significantly greater reductions in the mean Irritability subscore as compared to placebo (56.9\% vs. $14.1 \%)$. The effect size for risperidone was 1.2 at the end of the 8-week trial. Risperidone was also significantly more likely to produce a positive response $(69 \%)$ compared to placebo $(12 \%)$. Positive response was defined as a $25 \%$ decrease in the Irritability subscore and a rating of "much improved" or "very much improved" on the Clinical Global Impressions-Improvement (CGI-I) scale. Regular monitoring of side effects did not reveal any extrapyramidal symptoms (EPS) and no child required discontinuation due to side effects. A significantly greater mean increase in weight occurred in the risperidone group $(2.7 \pm 2.9 \mathrm{~kg})$ as compared to placebo $(0.8 \pm$ $2.2 \mathrm{~kg}$ ), and proportions of subjects receiving risperidone were significantly more likely to experience mild $(49 \%)$ or moderate $(24 \%)$ increases in appetite, fatigue (59\%), drowsiness $(49 \%)$, drooling $(27 \%)$, and dizziness $(16 \%)$.

This study did employ selection criteria that included subjects with baseline levels of aggression and SIB. The sample size was adequate, but the observation period was only 8 weeks long, and does not provide data about sustained benefit and long-term tolerability. In addition, given concerns about dose-related side effects with risperidone, the minimal effective dose cannot be determined from these results.

As part of the initial 8-week phase of the RUPP trial, Arnold et al. (2003) asked parents to identify one or two chief complaints of their child's behavior at baseline. Parents provided full descriptions of these symptoms, including 


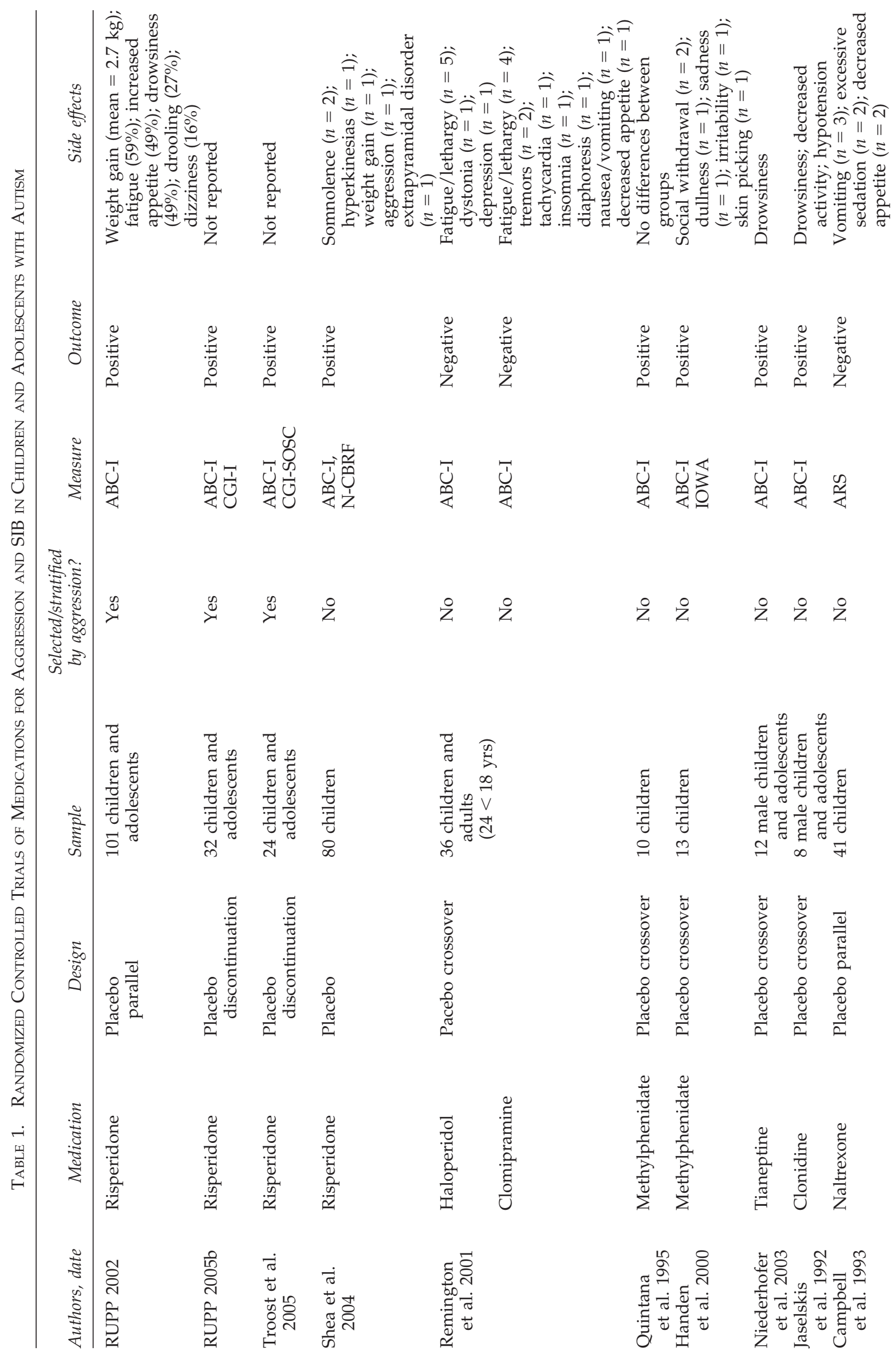




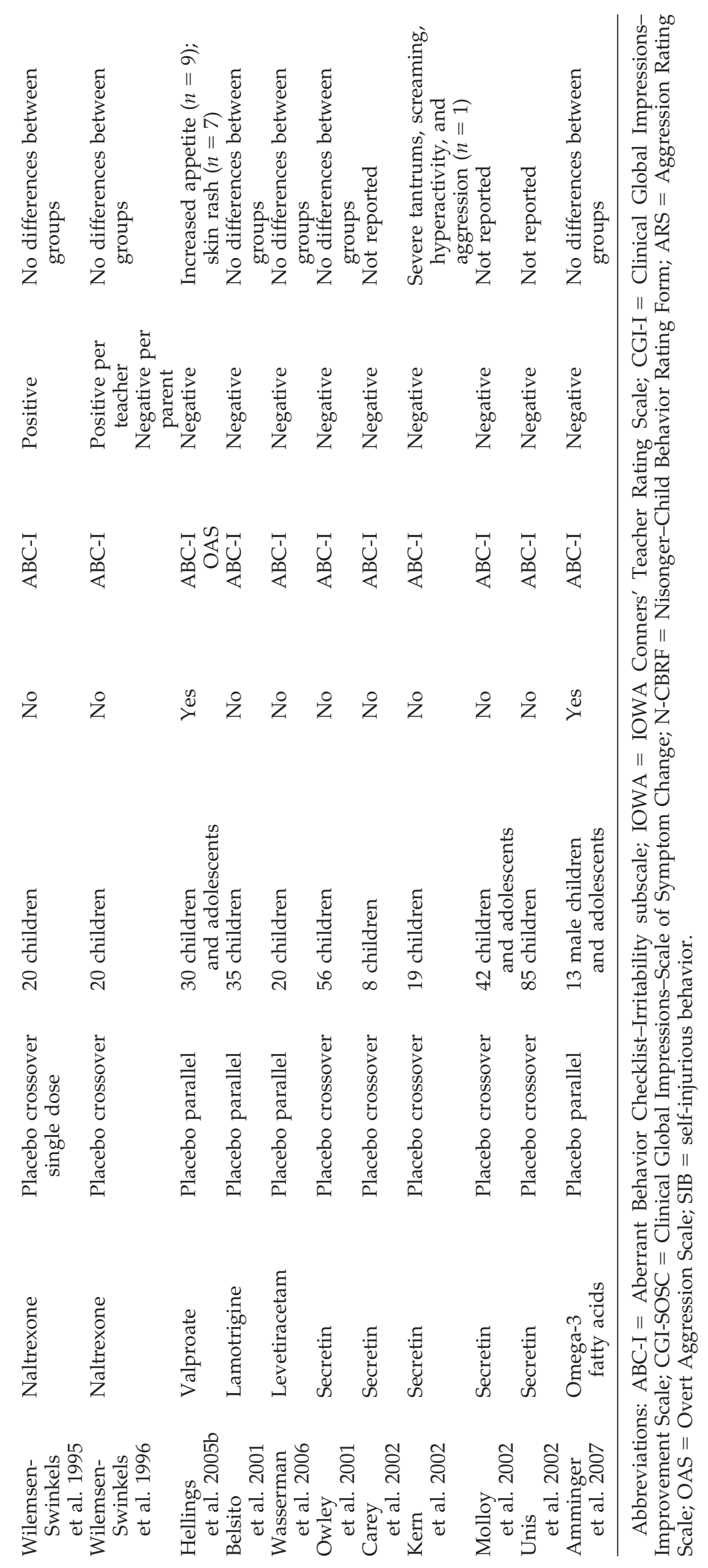


frequency, duration, intensity, and ability to interfere with daily life. At each subsequent visit, parents were asked to describe how the identified symptoms had changed since beginning the trial and these descriptions were then recorded and rated by independent, blinded judges on a 9-point scale. Among the symptoms identified by parents in this study, selfinjury (effect size $=2.11$ ) and aggression (effect size $=1.66)$ showed the greatest improvement in subjects who received risperidone.

At the end of the initial 8-week RUPP trial, participants who showed a positive response to risperidone were enrolled in an extension study (RUPP 2005b). A 4-month open-label phase was followed by an 8-week doubleblind, placebo-controlled, parallel-group discontinuation trial. In the placebo arm of this discontinuation trial, risperidone was gradually replaced by placebo over 4 weeks, followed by a 4 -week period in which subjects received placebo alone. In the risperidone arm of this discontinuation study, risperidone dosage was maintained. Behavioral relapse was defined as a $25 \%$ increase in the ABC-I subscale and a rating of "much worse" or "very much worse" for at least two consecutive weeks on the CGI-Scale of Symptom Change. Thirty two subjects completed the discontinuation trial, and interim analysis revealed a $62.5 \%$ rate of behavioral relapse for subjects in the placebo arm as compared to $12.5 \%$ for subjects who continued to receive risperidone. The discontinuation trial was then terminated by the National Institute of Mental Health (NIMH) Data and Safety Monitoring Board on the basis of these interim results. Although the study did select subjects based on levels of aggression, interpretation of its results is limited by the fact that only those participants who responded to risperidone were included in this extension study. Furthermore, the validity of discontinuation trials may be called into question given the risk of discontinuation symptoms, despite the taper, and the potential for blinding to have been compromised.

Troost et al. (2005) conducted the second $\mathrm{RCT}$ that used a standardized measure of aggression to examine the efficacy of risperidone in children and adolescents with pervasive developmental disorders (PDD). After an initial 24-week open-label phase, 24 responders were identified for entry into an 8-week doubleblind, placebo-controlled, parallel-group discontinuation phase. In the placebo group, risperidone was gradually replaced by placebo over a period of 3 weeks, followed by placebo alone for 5 weeks. In the risperidone group, dosages were maintained for 8 weeks. The mean age of the subjects was 9 years. For subjects who remained on risperidone, the mean dose was $1.81 \mathrm{mg} /$ day. Relapse was defined as a $25 \%$ increase in the ABC-I subscale and a rating of "much worse" or "very much worse" for at least 2 consecutive weeks on the CGI-Scale of Symptom Change in reference to behavior. At study end point, significantly more subjects relapsed in the placebo group (67\%) as compared to those who continued to receive risperidone $(25 \%)$. Over the duration of the discontinuation phase, subjects who received placebo also showed a significantly greater increase in ABC-I subscore (60\%) as compared to risperidone (14\%).

This study did select subjects with aggression and SIB, but other potential confounders limited interpretation of the results. As with the RUPP discontinuation study, only responders to the open-label trial were selected for inclusion in the placebo-controlled phase; the nature of the design may also increase the likelihood of relapse, increase the risk of other discontinuation side effects, and compromise blinding. In addition, these results may have been influenced by type I error because of small samples in each treatment arm $(n=12)$. Other limitations include the overrepresentation of relatively high-functioning male children (90\%) and subsequent difficulty generalizing these results to lower functioning, female, or adolescent populations.

The third RCT of risperidone was conducted in 80 children and adolescents with pervasive developmental disorders by Shea et al. (2004) using a double-blind, placebo-controlled, parallel-group design over 8 weeks. Subjects ranged in age from 5 to 12 years old (mean = 7.5) and risperidone was administered at a mean dose of $1.17 \mathrm{mg} /$ day $(0.04 \mathrm{mg} / \mathrm{kg}$ per day). The ABC-I subscale was the primary outcome measure of aggression and the Nisonger Child Behavior Rating Form (N-CBRF), which 
includes a conduct problem subscale, was also used. Mean ABC-I scores decreased for both groups at each weekly visit, although the mean decrease in subjects receiving risperidone was significantly greater as compared to placebo. Over the duration of the study period, subjects receiving risperidone had approximately twice the mean decrease in ABC-I subscore as compared to placebo. Significantly lower scores on the N-CBRF conduct problem subscale were also found in the risperidone group. There were no significant differences in the incidence of EPS between the two groups according to the Extrapyramidal Symptom Rating Scale. Subjects who received risperidone gained significantly more weight on average $(2.7 \mathrm{~kg})$ than those on placebo $(1.0 \mathrm{~kg})$. The most common adverse events experienced by subjects in the risperidone group were somnolence $(72.5 \%)$, upper respiratory tract infection $(37.5 \%)$, rhinitis $(27.5 \%)$, and increased appetite $(22.5 \%)$. Among those who reported somnolence in the risperidone group, resolution was achieved in the majority of cases (86.2\%) through dose reduction or no action. Among the 40 subjects in the risperidone group, 5 experienced adverse events that were considered severe: hyperkinesia and somnolence $(n=1)$; severe weight gain $(n=1)$; somnolence $(n=1)$; aggressive reaction with impaired concentration $(n=1)$; and extrapyramidal disorder as a result of accidental overdose $(n=1)$. Aside from weight gain, the authors did not report whether the rates of any of these adverse events differed between the risperidone and placebo groups. Limitations of this study include its short duration and the fact that subjects were not selected or stratified according to baseline levels of aggression.

\section{Haloperidol}

One RCT has examined the efficacy of haloperidol, a dopaminergic antagonist, with a standardized outcome measure of aggression and self-injurious behavior in children with autism. In their study, Remington et al. (2001) compared clomipramine, haloperidol, and placebo in 36 subjects over 7 weeks using a double-blind, placebo-controlled, crossover design with 1-week washout periods separating the three treatment arms. Subjects ranged in age from 10 to 36 years $($ mean $=16.3)$ and 24 subjects were less than 18 years of age. All met the Diagnostic and Statistical Manual for Mental Disorders (DSM-IV) (American Psychiatric Association 1994) criteria for autism. Haloperidol was administered in a daily dose of 1.3 $\mathrm{mg} /$ day. The ABC-I subscale was the primary outcome measure of aggression and self-injurious behavior. No significant difference was found in aggression and self-injury with haloperidol as compared to placebo controls. A global side effects scale and the Extrapyramidal Symptom Rating Scale were used to monitor medication tolerability. Ten of 33 subjects prematurely discontinued the haloperidol treatment arm due to "behavioral problems" $(n=3)$, fatigue/lethargy $(n=5)$, depression $(n=1)$, and dystonia $(n=1)$. Eleven of 32 subjects prematurely discontinued the placebo arm due to "behavioral problems" $(n=10)$ and nosebleeds $(n=1)$.

Subjects in this study were not selected for aggression, and these results may also be called into question by the presence of possible carryover effects between treatment groups and placebo. In addition, the daily dose of haloperidol (1.3 mg) may not have been sufficient to produce meaningful therapeutic benefit.

\section{Methylphenidate}

Two RCTs have utilized a primary outcome measure of aggression to examine the efficacy and tolerability of methylphenidate, a dopaminergic agonist, in children and adolescents with autism. Quintana et al. (1995) conducted the first study in 10 subjects with autism over 4 weeks using a double-blind, placebo-controlled, crossover design. Subjects ranged in age from 7 to 11 years (mean $=8.5$ ). Methylphenidate was administered in divided doses equaling 20 and $40 \mathrm{mg} /$ day. The ABC-I subscale was the primary outcome measure of aggression and SIB and was completed independently by two psychiatrists during 3-hour observation sessions that included a simulated structured classroom situation with classroom tasks and free play. From a mean baseline subscore of $11.8 \pm 11.2$, methylphenidate produced significant improvements in ABC-I 
mean endpoint subscore $(4.0 \pm 3.8)$ as compared to placebo mean endpoint score (7.2 \pm 6.3) $(p<0.01)$. Tolerability was assessed using a side effects checklist and no significant differences were found in the rates of side effects between methylphenidate and placebo.

Handen et al. (2000) conducted the second RCT of methylphenidate in 13 children diagnosed with autism or PDD not otherwise specified (NOS) over 7 days using a double-blind, placebo-controlled, crossover design. Subjects ranged in age from 5.6 to 11.2 years (mean = 7.4). Methylphenidate was administered in low $(0.3 \mathrm{mg} / \mathrm{kg}$ per dose $)$ and high $(0.6 \mathrm{mg} / \mathrm{kg}$ per dose) doses two to three times daily. Primary outcome measures of aggression were the ABC-I subscale and the aggression subscale of the IOWA Conners' Teacher Rating Scale. As compared to placebo, subjects who received methylphenidate showed significant improvement on both outcome measures. A side effects checklist was used to assess tolerability. A relatively high number of subjects (9 of 12) reportedly experienced some "side-effects" while on placebo. A total of 5 children experienced severe side effects while receiving methylphenidate, including social withdrawal, dullness, sadness, irritability, and skin picking. These side effects caused three subjects to be discontinued from the study.

Both RCTs of methylphenidate studies produced significant results, but several shortcomings are notable. Sample sizes were small and the study duration was relatively short. Furthermore, subjects were not stratified according to levels of aggression and a wide range of behaviors was noted among subjects at baseline.

\section{Clomipramine}

Two RCTs have used standardized outcome measures of aggression in examining the use of serotonergic medications as a treatment for children and adolescents with autism. The first was the aforementioned study by Remington et al. (2001). Clomipramine doses began at 25 $\mathrm{mg} /$ day and were titrated to an average final dose of $128.4 \mathrm{mg} /$ day. The Irritability subscale of the $\mathrm{ABC}$ was the primary outcome measure of aggressive and self-injurious behavior. The results of this study did not demonstrate a significant difference between clomipramine and placebo scores on the ABC-I subscale. Twenty subjects discontinued clomipramine prior to week 7 , and 12 cited side effects as the reason: fatigue/lethargy $(\mathrm{n}=4)$, tremors $(n=2)$, tachycardia $(n=1)$, insomnia $(n=1)$, diaphoresis $(n=1)$, nausea/vomiting $(n=1)$, and decreased appetite $(n=1)$. The remaining 8 subjects discontinued specifically because of "behavioral problems," reportedly due to lack of drug efficacy.

The results of this study must be interpreted with caution, however, because significantly fewer subjects in the clomipramine group were able to complete the trial. In addition, potential carryover effects likely exist when these medications are used in sequence with only 1-week washout periods and may have artificially inflated the placebo effect. Subjects were also not stratified according to baseline levels of aggression and this may impact the validity of post-intervention assessments.

\section{Tianeptine}

The second RCT of a serotonergic medication examined tianeptine, an agent that reportedly increases serotonin reuptake (Sweetman 2004). Tianeptine was studied by Niederhofer et al. (2003) in 12 male children with autism over 12 weeks using a double-blind, placebo-controlled, crossover design. Subjects ranged in age from 4.2 to 14.9 years (mean $=7.3$ ). Tianeptine was administered in a dose of $37.5 \mathrm{mg}$ daily. The ABC was completed by parents and teachers and the Irritability subscale was used as the primary outcome measure of aggressive and self-injurious behavior. At study endpoint, results indicated a significant difference between tianeptine and placebo on the ABC-I subscale according to parent and teacher ratings, although this difference was not significant at the study midpoint of 6 weeks. Medication tolerability was monitored using a symptom checklist of potential side effects. Drowsiness and decreased activity were significantly increased in patients receiving tianeptine at both 6 and 12 weeks.

Several methodological limitations of this study also need to be considered. Only 12 sub- 
jects were included and the sample was not stratified using baseline assessments of aggression. It is also important to note that clinician ratings did not demonstrate a significant difference between tianeptine and placebo, although the trial duration may not have been sufficient to assess the therapeutic benefit fully. Due to increased rates of drowsiness among subjects who received tianeptine, parents and teachers may have effectively become unblinded. Finally, because this study used a crossover design with only a 1-week washout period, carry-over effects are also possible.

\section{Clonidine}

One RCT has used a standardized outcome measure to examine the ability of an adrenergic agent to reduce aggression and SIB in children and adolescents with autism. Jaselskis et al. (1992) conducted a study of clonidine in 8 male subjects with autism for 6 weeks using a doubleblind, placebo-controlled, crossover design. Subjects ranged in age from 5 to 13.4 years (mean $=$ 8.1). Clonidine was administered in daily doses of 0.15 to $0.20 \mathrm{mg} /$ day. Teacher rating of the ABC-I subscale was the primary outcome measure of aggression and self-injury. The results of this study demonstrated that children who received clonidine had significantly lower ABC-I subscale scores as compared to placebo. Clonidine was significantly more likely to cause drowsiness and decreased activity, and the onset of hypotension necessitated dose reduction in 3 children during the study.

Clinician ratings were not sensitive to effects for clonidine, however, and several limitations may have biased these results. The sample size was small and subjects were not selected for aggressive behavior. Six weeks may also not have been a sufficient duration to detect full therapeutic benefit, and crossover effects may have played a role despite the 1-week washout period in between arms. Finally, the greater likelihood of drowsiness among subjects who received clonidine may have compromised the blinding of parents and teachers.

\section{Naltrexone}

Three RCTs have used a standardized primary outcome measure of aggression to exam- ine the efficacy of naltrexone in children with autism. The first was conducted by Campbell et al. (1993) in 41 children diagnosed with autistic disorder using a double-blind, placebo-controlled, parallel-group design over 4 weeks. Subjects ranged in age from 2.9 to 7.8 years (mean $=4.9)$. Naltrexone was administered in a daily dose of $0.5 \mathrm{mg} / \mathrm{kg}$ for 1 week, and then increased to $1.0 \mathrm{mg} / \mathrm{kg}$ for 2 weeks. After 3 weeks, all subjects entered a 1-week post-treatment placebo phase. The Aggression Rating Scale was the primary outcome measure of aggression and self-injury. There was no significant improvement in the severity of SIB or aggression in subjects receiving naltrexone as compared to placebo. Overall, adverse effects were reportedly similar in nature and frequency between the two groups; excessive sedation $(n=3)$, decreased appetite $(n=2)$, and vomiting $(n=3)$ were only observed in children who received naltrexone. This study did not select or stratify subjects according to levels of aggression and it is possible that the dose of naltrexone was not sufficient to achieve therapeutic benefit.

Willemsen-Swinkels et al. (1995) conducted the second RCT of naltrexone in 20 children with autism using a double-blind, placebo-controlled, single-dose, crossover design. Subjects ranged in age from 3 to 7 years (mean $=5.5$ ). Naltrexone was administered in a single dose of $40 \mathrm{mg}(1.48 \mathrm{mg} / \mathrm{kg}$ to $2.35 \mathrm{mg} / \mathrm{kg}$; mean = $1.96 \mathrm{mg} / \mathrm{kg}$ ). The ABC-I subscale was the primary outcome measure of aggression and selfinjury. Naltrexone produced a significantly greater reduction in the ABC-I subscore as compared to placebo. Plasma $\beta$-endorphin levels and liver function were monitored and remained within normal limits after administration of naltrexone.

In an extension of this study, WillemsenSwinkels et al. (1996) examined the effects of longer-term administration of naltrexone in 20 children with autism using a double-blind, placebo-controlled, crossover design over 8 weeks (4 weeks in each treatment arm). Naltrexone was administered in doses that ranged from $0.74 \mathrm{mg} / \mathrm{kg}$ per day to $1.18 \mathrm{mg} / \mathrm{kg}$ per day (mean $=0.98 \mathrm{mg} / \mathrm{kg}$ per day). Parents and teachers completed the ABC-I subscale as the primary outcome measure of aggressive and 
self-injurious behavior. The results of this study did not demonstrate significant differences between placebo and naltrexone in ABCI subscores as rated by the parents. However, teacher ratings of the ABC-I subscores did show significant improvement with naltrexone. No serious adverse effects were reported.

These results are confounded by the relative absence of aggression at baseline; only 2 of the 20 subjects reportedly demonstrated "mild SIB." Despite producing a significant effect in the first of these two studies, the limitations of a one-time dose of naltrexone are self-evident. Interestingly, the 8-week follow-up study did not produce significant results, except on teacher ratings. The inconsistency between parent and teacher ratings calls these results into question, especially given the absence of blinded clinician ratings.

\section{Valproate}

One RCT has utilized a standardized assessment of aggression and self-injury to examine the efficacy of valproate in children and adolescents with autism, Asperger syndrome, and PDD-NOS. Hellings et al. (2005b) studied a sample of 30 subjects using a double-blind, placebo-controlled, parallel-group design over 8 weeks. Subjects ranged in age from 6 to 20 years. Subjects were required to exhibit significant aggression to self, others, or property at least three times per week for inclusion in the trial. Valproate was administered in doses of $20 \mathrm{mg} / \mathrm{kg}$ per day. The ABC-I subscale and the Overt Aggression Scale (OAS) were used to assess aggression and self-injury. No significant differences emerged between treatment groups on either the ABC-I subscale or the OAS. Side effects were measured by a checklist derived from the Physicians' Desk Reference. Subjects in the valproate group were significantly more likely to report increased appetite $(n=9)$. Other side effects included weight gain $(n=7)$, skin rash $(n=6)$, nausea $(n=4)$, vomiting $(n=$ $4)$, diarrhea $(n=4)$, fever $(n=4)$, drowsiness $(n=3)$, lethargy $(n=3)$, chills $(n=3)$, and constipation $(n=2)$, but these did not differ significantly between valproate and placebo.

This study did select subjects for aggression and SIB. However, the authors reported high intrasubject variability in severity and frequency of aggression during the 8-week period, which likely weakens study power. Results must also be interpreted with caution because of small group sizes and a high placebo response rate. In addition, the duration of the study may not have been sufficient. After a 1week placebo run-in and valproate titration, adequate doses were only maintained for approximately 4 weeks. Finally, mean valproate blood level was $77.7 \mathrm{mcg} / \mathrm{dL}$ at week 8 , and higher doses/blood levels may be required to achieve meaningful benefit and demonstrate statistical separation from placebo.

\section{Lamotrigine}

Belsito et al. (2001) conducted the only RCT of lamotrigine to use a standardized assessment of aggression and self-injury in 35 youths with autism. The authors used a double-blind, placebo-controlled, parallel-group design over 18 weeks. Subjects ranged in age from 3 to 11 years $($ mean $=5.8)$. Lamotrigine was titrated to a mean dose of $5 \mathrm{mg} / \mathrm{kg}$ per day over 8 weeks, and was then maintained for an additional 4 weeks. Following the titration and maintenance phases, subjects were tapered over 2 weeks and then entered a final 4-week drugfree phase. The ABC-I subscale was the primary outcome measure of aggression and selfinjury. No significant differences were found between ABC-I subscores in children receiving lamotrigine and those on placebo. All subjects were monitored for side effects, and rates did not differ significantly between groups. This study did not select for subjects with aggression at baseline and groups were not stratified according to levels of aggression. Small group sizes may also have weakened the power to detect significant differences between lamotrigine and placebo. Furthermore, subjects were only maintained on a therapeutic dose of lamotrigine for 4 weeks and this may not have been of sufficient duration to assess benefit.

\section{Levetiracetam}

One RCT has utilized a standardized outcome measure of aggression to examine the efficacy of levetiracetam in children with autism. 
Wasserman et al. (2006) studied 20 children with autism spectrum disorders using a double-blind, placebo-controlled, parallel-group design over 10 weeks. Participants ranged in age from 5 to 17 years (mean $=8.72$ ). Levetiracetam was titrated to a mean dose of 862.50 $\mathrm{mg} /$ day. Parent and teacher ratings of the ABC-I subscale were used to monitor aggressive behavior in the study subjects. No significant differences were found between parent ratings of the ABC-I subscale in subjects receiving levetiracetam and those on placebo. Teacher ratings, on the other hand, showed a significant time by treatment interaction, indicating that the levetiracetam group increased in irritability, whereas the placebo group became less irritable. Tolerability was monitored via regular reports of side effects, although statistical analyses of the side effect reports are not presented Participants receiving placebo experienced agitation $(n=1)$, aggression $(n=1)$, enuresis $(n=1)$, and insomnia $(n=1)$. In the levetiracetam group, participants experienced agitation $(n=1)$, aggression $(n=2)$, hyperactivity $(n=1)$, impulsivity $(n=1)$, loss of appetite $(n=1)$, self-injurious behavior $(n=1)$, weight gain $(n=1)$, and weight loss $(n=1)$. Two subjects in the placebo group withdrew from the study, 1 due to increased hyperactivity, and 1 due to seizure. One subject in the levetiracetam group dropped out from the study due to lack of efficacy. Interpretation of the study is limited by the small sample size and by the inconsistency between parent and teacher ratings of the ABC-I subscale. Also, study participants were neither selected nor stratified according to baseline levels of aggression.

\section{Secretin}

Five RCTs have used a standardized outcome measure of aggression and self-injury to examine the use of secretin in children and adolescents with autism or PDD-NOS. All five used a double-blind, placebo-controlled, single-dose, crossover design over 3-6 weeks (Owley et al. 2001; Carey et al. 2002; Kern et al. 2002; Molloy et al. 2002; Unis et al. 2002). Sample sizes ranged from 8 (Carey et al. 2002) to 85 (Unis et al. 2002) children and adolescents aged
3 to 15 years. Secretin was always administered in a one-time infusion of $2 \mathrm{CU} / \mathrm{kg}$ or its equivalent and assessments were then collected over the duration of the studies using the ABC-I subscale as the primary outcome measure of aggression and self-injury. None of the studies found significant differences in ABC-I subscores between subjects who received secretin and those who received saline infusion. Post hoc analysis of one study (Kern et al. 2002) found that children with a history of chronic diarrhea who received secretin showed significant improvement in the ABC-I subscore as compared to baseline, and these improvements were not found in children who received placebo. Adverse effects were not systematically assessed, although one study (Owley et al. 2001) reported abdominal rash $(n=1)$, nonfebrile seizures $(n=1)$, and vomiting $(n=2)$ in children receiving secretin. In another study (Kern et al. 2002), one subject was noted to exhibit dramatic increases in tantrums, screaming, hyperactivity, and aggression following secretin infusion. Although replication across studies makes the results appear convincing, none of these studies selected subjects according to baseline levels of aggression or later stratified the samples to assess differential effects. In addition, all used a single dose of secretin that may have been insufficient and the effect of multiple doses has not been tested in a placebo-controlled design.

\section{Omega-3 fatty acids}

One RCT examined the efficacy of omega-3 fatty acids in children with autistic disorder using a standardized assessment of aggression and self-injury. Amminger et al. (2007) studied 13 boys using a double-blind, placebo-controlled, parallel-group design over 6 weeks. Selection criteria for the study included an age of 5-17 years, a mental age of at least 18 months, and a score of greater than 17 on the ABC-I subscale. The mean age of subjects receiving omega-3 fatty acids was 10.5 years. The mean age in the placebo group was 12.1 years. Participants in the experimental group received 1.5 grams / day of omega-3 fatty acids (0.84 grams / day of eicosapentaenoic acid, and 0.7 grams/ day of docosahexaenoic acid). The ABC-I sub- 
scale was used to assess aggressive and selfinjurious behavior. No statistically significant differences were found between treatment groups in scores or improvements on the ABCI subscale. Although no standardized assessments of adverse effects appear to have been conducted, fever was reported in the experimental group and headache and insomnia were reported in the placebo group.

This study did select subjects for aggression by requiring a minimum score on the ABC-I subscale. Nevertheless, interpretation of the study's results is limited by its small group sizes and short study duration. If imbalances of these nutrients play a critical role in brain function and development, it is possible that therapeutic benefit may not occur within 6 weeks.

\section{DISCUSSION}

Among the 21 randomized controlled studies to employ a standardized primary outcome measure of aggression or self-injury to examine the efficacy of medication in children with autism, five medications produced significant results as compared to placebo. These medications include risperidone, methylphenidate, tianeptine, clonidine, and naltrexone.

Risperidone is the medication with the most evidence to support its use for aggression and SIB in children and adolescents with autism. Results are also consistent across several studies with similar designs, particularly those conducted by the RUPP (2005b) and Troost et al. (2005). Furthermore, this medication recently received an indication by the FDA for aggression toward others and deliberate self-injurious behavior in autism (FDA 2006). Although it has been suggested that symptom improvement may only occur as a result of sedation, post hoc analysis in one study (Shea et al. 2004) found comparable changes in ABC-I subscores between risperidone-treated subjects who experienced somnolence and those who did not. In contrast to the first-generation antipsychotic (FGA) haloperidol, this second-generation antipsychotic (SGA) appears to be both effective and well-tolerated. According to studies in adult populations with schizophrenia, risperi- done also has a lower risk of EPS and tardive dyskinesia (Dossenbach et al. 2004; Schooler et al. 2005). This difference is believed to arise from blockade of serotonin-type 2 receptors (Findling et al. 1997; Masi et al. 2003). Combined serotonergic activity of risperidone may also contribute to its effectiveness in reducing aggressive behavior in children with autism. Yet, all SGAs combine dopamine and serotonin antagonism in their mechanism of action, and only risperidone has been studied under placebo-controlled conditions for the treatment of aggression in autism. Placebo-controlled trials of other SGAs are needed to determine if there are effective alternatives to risperidone among this class of medications. The risks of risperidone include significant weight gain and increased vulnerability to diabetes and cardiovascular disease later in life. The metabolic syndrome, characterized by obesity, dyslipidemia, and abnormalities of glucose homeostasis, has also been described in adult populations treated with SGAs (Mackin et al. 2005). Therefore, nutritional counseling and a physical activity regimen should be included for all children treated with risperidone.

In addition to weight gain, hyperprolactinemia has arisen as a safety concern with the use of risperidone. The release of the hormone prolactin is mediated by dopaminergic inhibition, and dopamine antagonists may consequently increase prolactin secretion. Anderson et al. (2007) conducted an analysis of the RUPP 8week randomized controlled trial of risperidone in 101 children with autism discussed above. They found significant elevations in prolactin levels in subjects treated with risperidone as compared to placebo controls. An additional, open-label study of children with autism treated with risperidone found two-fold increases in serum prolactin levels over a period of at least 26 weeks (Hellings et al. 2005c). Other studies have reported similar prolactin elevations in children, adolescents, and adults treated with risperidone (Malone et al. 2002; Patel et al. 2005). Hyperprolactinemia may result in galactorrhea, dysmenorrhea, sexual dysfunction, and osteoporosis in females, and can lead to gynecomastia, erectile difficulties, and impaired spermatogenesis in males (Haddad and Wieck 2004). However, there is evidence 
that prolactin release may gradually diminish to near-normal levels over long-term risperidone use and that hyperprolactinemia is not associated with any interference in growth or sexual maturation (Malone et al. 2002; Patel et al. 2005; Anderson et al. 2007). In the absence of clinical signs, the utility of monitoring prolactin levels in patients treated with risperidone remains an area of debate. Additional long-term studies are needed to understand the impact of risperidone treatment in children and adolescents with autism. Another related issue that warrants further study is the differential effect of dosing on the risk of metabolic and endocrine changes.

Two RCTs found methylphenidate to improve symptoms of aggression and SIB effectively in children and adolescents with autism. The predominant symptoms that stimulant medications target are hyperactivity, attention deficit, and impulsivity. Past studies have found stimulants, such as methylphenidate, to be both efficacious and tolerable in treating populations with autism (Hoshino et al. 1977; Birmaher et al. 1988; Strayhorn et al. 1988). A double-blind, placebo-controlled study conducted by the RUPP, for example, found significant improvements in ABC-hyperactivity subscores in 72 children with autism spectrum disorders who were treated with methylphenidate as compared to placebo. It is important to note that the ABC-I subscale was a secondary outcome measure of this study, but that no significant improvements in Irritability subscores were found between those receiving methylphenidate and those on placebo (RUPP 2005a). The two RCTs included in this review were the only to use an assessment of aggression and SIB as primary outcome measures and both studies demonstrated significant improvements overall. There were reports of worsening irritability and self-injury in some individuals, although the specific number of subjects who experienced such paradoxical effects was not reported. Previous studies have also documented paradoxical reactions to stimulants, particularly in developmentally disabled populations (Handen et al. 1991; RUPP 2005a), highlighting the need to exercise caution in prescribing these medications in children and adolescents with autism. Nevertheless, stimulant medications such as methylphenidate are generally well tolerated and effective in children and adolescents with ADHD (Greenhill et al. 2001). In general, and specifically with methylphenidate, clinical trials to assess the effects of treatment on aggressive behavior in children with autism should either select subjects with aggression or stratify the sample according to baseline levels. Analyses may then reveal a subset of children with autism that reliably respond to methylphenidate treatment. The effect of stimulants in individuals with autism spectrum disorders is likely less reliable than in typically developing children with ADHD, but additional placebo-controlled studies are nevertheless warranted.

Tianeptine is reported to be a serotonin reuptake enhancer and an anxiolytic medication that is approved and marketed in a number of countries in Europe, Asia, and Latin America (Sweetman 2004). While potentially effective, its practical application for children with autism in the United States is limited at this time. The endorsement of this medication for the treatment of aggression in autism is also challenged by the presence of only one placebocontrolled study with several methodological limitations. In addition, the tolerability of tianeptine requires further study.

Despite theoretical support for adrenergic dysregulation as an etiological factor in aggression, only one RCT has examined this system as a pharmacological target in children with autism. The results demonstrate that clonidine improves symptoms of aggression in autism. However, clonidine did produce a significant increase in drowsiness, which therefore introduces the possibility that effects on aggression may have occurred secondary to sedation. In addition, the risk of hypotension warrants close monitoring. The results of this trial are compelling, but additional placebocontrolled studies are needed to replicate these findings and clarify issues of tolerability.

With regard to the efficacy of naltrexone in treating aggression and self-injury in children with autism, results are equivocal. In one of the three RCTs, no significant improvement was found in the severity of SIB or aggression in subjects receiving naltrexone (Campbell et al. 1993). The second study found that a single 
dose of naltrexone produced significant effects, but only 2 of the 20 children enrolled in the study manifested symptoms of self-injury at baseline (Willemsen-Swinkels et al. 1995). In a follow-up to this study, subjects maintained improvement on naltrexone over 8 weeks, but only according to teacher ratings and not parent ratings (Willemsen-Swinkels et al. 1996). Much effort has been dedicated to identifying a subset of children with autism that respond to naltrexone based on evidence that individuals with autism have elevations in plasma $\beta$-endorphin concentrations (Sandman 1988; Ernst et al. 1993; Bouvard et al. 1995; Cazzullo et al. 1999; Leboyer et al. 1999). Some have suggested an association between higher levels of endogenous opiates and elevated rates of selfinjury (Gillberg 1995) or an ability to predict SIB based on plasma concentration levels (Sandman 1988), yet others found no such relationship (Ernst et al. 1993; WillemsenSwinkels et al. 1995). Research on the effect of naltrexone on $\beta$-endorphin levels in individuals with autism remains similarly inconclusive. Studies have reported that naltrexone produces no change (Willemsen-Swinkels et al. 1995), significant increases (Zingarelli et al. 1992), and significant decreases (Bouvard et al. 1995; Cazzullo et al. 1999) in plasma levels of $\beta$-endorphin in individuals with autism. Few studies have systematically assessed side effects of naltrexone in children with autism, although most describe it as safe and well tolerated. Side effects are reportedly mild, and rates are comparable to placebo (Elchaar et al. 2006). The endogenous opioid system was once considered a promising line of study; however, recent efforts to pursue this system as a medication target in autism have waned. Current results are inconsistent and additional studies are likely required before naltrexone may be considered a reliable option for treating aggression and SIB in autism.

Placebo-controlled studies have also assessed the efficacy of clomipramine and haloperidol, secretin, omega-3 fatty acids, valproate, lamotrigine, and levetiracetam, although results to date do not show significant benefit in treating aggression. Secretin, in particular, has been examined in five RCTs, none of which demonstrated significant results.
Clomipramine also failed to demonstrate significant improvement in aggression and SIB, but this trial represents the only attempt to study a serotonin reuptake inhibitor for aggression in autism. This is despite evidence from several open-label and placebo-controlled studies of selective serotonin reuptake inhibitors in treating associated symptoms of autism, such as repetitive behavior (Fatemi et al. 1998; Couturier and Nicolson 2002; Namerow et al. 2003; Owley et al. 2005). The serotonergic system remains a compelling candidate for targeted treatment aimed at reducing aggression and SIB in autism.

Omega-3 fatty acids, valproate, lamotrigine, and levetiracetam studies do not have convincing data that demonstrate improvement in aggression and SIB among children and adolescents with autism according to the results of this review. However, only one RCT was done to examine the efficacy of each. In addition, an open-label extension trial at the end of the valproate RCT (Hellings et al. 2005b) found that attempts to taper the medication resulted in a worsening of irritability and aggression. Although these results must be interpreted with caution, combined with results from an openlabel study (Hollander et al. 2001), evidence remains to suggest that a subgroup of individuals with autism may experience improvement in aggression with valproate. Additional placebo-controlled trials are necessary and known to be in progress or under review. It is also important to note that there is a higher risk of life threatening rash with lamotrigine in pediatric patients than in adults (Physicians' Desk Reference 2006).

The treatment of autism requires targeted approaches to different symptom domains. This review selected aggression and SIB because of the frequent need for pharmacological intervention and the relative paucity of effective treatment options. Whereas this review is both comprehensive and focused, it is nonetheless important to delineate some weaknesses. First, few of the studies we reviewed selected sample populations on the basis of aggression. Future studies would be strengthened by utilizing such selection criteria or by stratifying subjects according to baseline levels of aggression. 
Second, in an effort to assess specifically the impact of medication on aggression and SIB, we focused only on studies that employed at least one primary outcome measure of aggression. Yet, few studies specifically examined aggression using such measures, and in those that did, the ABC-I subscale was the predominant instrument. This subscale includes questions to assess aggression and self-injury, but may not be as specific as the OAS, for example, which includes direct measures of aggression directed at others, aggression toward property, and SIB (Hellings et al. 2005a). Nevertheless, the ABCI subscale has been validated as a tool to measure aggression in children (Aman et al. 1985) and did meet our a priori criteria.

Third, this review chose to focus only on studies that included children and adolescents in their sample. This criterion was used because aggression and SIB occur commonly in children with autism (RUPP 2002) and because less is known about the nature and impact of psychotropic medications in this population. However, studies in adult populations were excluded, and perhaps their inclusion would have altered our results. A marked difference in the efficacy and tolerability of medications in children and adolescents as compared to adults with autism has been documented in studies of fluvoxamine (McDougle et al. 1996b; Martin et al. 2003), for example, and this highlights the importance of considering developmental factors when prescribing these medications.

Finally, our criteria defined only randomized controlled trials for inclusion in this review, and, as a result, there is limited discussion of methodological weaknesses of the included studies. We sought to review only the most methodologically sound studies, but this selection bias should not imply that randomized controlled trials are beyond criticism, or that case reports, case series, and open-label trials are without merit.

\section{CONCLUSIONS}

The current state of evidence from randomized controlled clinical trials supports the use of risperidone and methylphenidate to treat symptoms of aggression and SIB in children and adolescents with autism and autism spectrum disorders. Several other medications have been studied using open-label designs and should be re-examined under placebo-controlled conditions. These medications include fluoxetine (Fatemi et al. 1998), citalopram (Couturier and Nicolson 2002; Namerow et al. 2003), escitalopram (Owley et al. 2005), mirtazapine (Posey et al. 2001), valproate (Hollander et al. 2001), olanzapine (Potenza et al. 1999; Kemner et al. 2002), and quetiapine (Martin et al. 1999; Findling et al. 2004). Additional RCTs may produce further evidence to support the use of these medications and provide a broader arsenal of treatment options for aggression and SIB in children and adolescents with autism.

Serotonin reuptake inhibitors, in particular, are a promising target for studies in the future. A recent RCT of fluoxetine in children with autism, for example, demonstrated significant benefit on repetitive behavior and no significant differences as compared to placebo in adverse effects, including agitation (Hollander et al. 2005a). However, worsening agitation has been reported across some studies of SSRIs in the treatment of autism (Fatemi et al. 1998; Couturier and Nicolson 2002, Namerow et al. 2003; Owley et al. 2005), and this emphasizes the need to exercise caution and careful monitoring of the use of serotonergic medications in this patient population. Subject selection criteria will also require careful consideration of the presence of agitation or mood cycling at baseline. Valproate is likewise deserving of additional RCTs. A recent RCT of valproate for the prevention of irritability associated with fluoxetine treatment in autism demonstrated significant benefit as compared to placebo (Anagnostou et al. 2006). Future studies of valproate will require careful consideration of dosing and blood levels as well as study duration to assess efficacy. Perhaps higher valproate blood levels and a longer treatment period will produce significant effects. Additionally, previous work has shown $\beta$-adrenergic antagonists, such as propranolol and nadolol, to have some efficacy in reducing aggressive behavior in individuals with mental retardation (Ratey et al. 1986). Because approximately $75 \%$ of children with autism suffer from co-morbid mental retarda- 
tion (Chakrabarti and Fombonne 2001), further studies should be conducted to determine the appropriateness of their use in children with autism.

In general, clinical trials in children and adolescents with autism should be initiated with low starting dosages and gradual titration schedules. As with other medications, benefits (both short-term as well as longterm) must be weighed against risks, and future research with larger samples and placebo-controlled designs will aid in that calculation. Further, future studies, controlled or otherwise, would benefit from systematic assessment of side effects to help clarify safety profiles and differentiate which medications within certain classes may be more likely to cause specific side effects. Likewise, improving our understanding of the nature and likelihood of medication side effects in populations with autism may help identify risk factors to predict in advance which individuals are most vulnerable.

Several challenges exist to designing valuable clinical trials and remain to be overcome. It is important to identify target symptoms and to develop better outcome measures to gauge improvement (Hollander et al. 2004). Standardized assessments of aggression and SIB, for instance, should therefore be incorporated into clinical trials in autism. Trials should also develop subject inclusion criteria that are realistic and can be generalized to clinical practice but that select subjects with aggression. Finally, an important direction for the future is to design studies that evaluate the efficacy and tolerability of these medications over both the short and long-term.

\section{DISCLOSURES}

Mr. Mihir Parikh and Dr. Alexander Kolevzon have no conflicts of interest or financial ties to disclose. Dr. Hollander receives support from NIH STAART Center of Excellence grant \#1U54 MH066673-01A1, Orphan Products Division of the Food and Drug Administration grant \#FD-R-001520-01-03, and an investigatorinitiated research grant from Lilly Research Labs (EH).

\section{REFERENCES}

Aman MG: Management of hyperactivity and other acting-out problems in patients with autism spectrum disorder. Semin Pediatr Neurol 11:225-228, 2004.

Aman MG, Singh NN, Stewart AW, Field CJ: Psychometric characteristics of the Aberrant Behavior Checklist. Am J Ment Defic 89:492-502, 1985.

American Psychiatric Association: Diagnostic and Statistical Manual of Mental Disorders, 4th ed. (DSM-IV). Washington (DC), American Psychiatric Association, 1994.

Amminger GP, Berger GE, Schafer MR, Klier C, Friedrich $\mathrm{MH}$, Feucht M: Omega-3 fatty acids supplementation in children with autism: A double-blind randomized, placebo-controlled pilot study. Biol Psychiatry 61:551553, 2007.

Anagnostou E, Esposito K, Soorya L, Chaplin W, Wasserman S, Hollander E: Divalproex versus placebo for the prevention of irritability associated with fluoxetine treatment in autism spectrum disorder. J Clin Psychopharmacol 26:444-446, 2006.

Anderson GM, Freedman DX, Cohen DJ, Doe A, Doe B: Whole blood serotonin in autistic and normal subjects. J Child Psych Psychiatry 28:885-900, 1987.

Anderson GM, Scahill L, McCracken JT, McDougle CJ, Aman MG, Tierney E, Arnold LE, Martin A, Katsovich L, Posey DJ, Shah B, Vitiello B: Effects of short- and long-term risperidone treatment on prolactin levels in children with autism. Biol Psychiatry 61:545-550, 2007.

Arnold LE, Vitiello B, McDougle CJ, Scahill L, Shah B, Gonzalez NM, Chuang S, Davies M, Hollway J, Aman MG, Cronin P, Koenig K, Kohn AE, McMahon DJ, Tierney E: Patient-defined target symptoms respond to risperidone in RUPP Autism Study: Customer approach to clinical trials. J Am Acad Child Adolesc Psychiatry 42:1443-1450, 2003.

Audenaert K, Laere KV, Dumont F, Siegers G, Mertens J, Heeringen Cv, Dierckx RA: Decreased frontal serotonin 5-HT receptor binding index in deliberate selfharm patients. Eur J Nuclear Med 28:175-182, 2001.

Baker SM: A biochemical approach to the problem of dyslexia. J Learn Disabil 18:581-584, 1985.

Barnard L, Young AH, Fearson J, Geddes J, O’Brien G: A systematic review of the use of atypical antipsychotics in autism. J Psychopharmacol 16:93-101, 2002.

Bekaroglu M, Aslan Y, Gedik Y, Deger O, Mocan H, Erduran E, Karahan C: Relationships between serum free fatty acids and zinc, and attention deficit hyperactivity disorder: A research note. J Child Psychol Psychiatry 37:225-227, 1996.

Bell JG, Sargent JR, Tocher DR, Dick JR: Red blood cell fatty acid compositions in a patient with autistic spectrum disorder: A characteristic abnormality in neurodevelopmental disorders? Prostaglandins Leukot Essent Fatty Acids 63:21-25, 2000.

Bell JG, MacKinlay EE, Dick JR, MacDonald DJ, Boyle RM, Glen AC: Essential fatty acids and phospholipase A2 in autistic spectrum disorders. Prostoglandins, Leukot, Essent Fatty Acids 71:201-204, 2004. 
Belsito KM, Law PA, Kirk KS, Landa RJ, Zimmerman AW: Lamotrigine therapy for autistic disorder: A randomized, double-blind, placebo-controlled trial. J Autism Dev Disord 31:175-181, 2001.

Berridge CW, Devilbiss DM, Andrzejewski ME, Arnsten AF, Kelley AE, Schmeichel B, Hamilton C, Spencer RC: Methylphenidate preferentially increases catecholamine neurotransmission within the prefrontal cortex at low doses that enhance cognitive function. Biol Psychiatry 60:1111-1120, 2006.

Birmaher B, Quintana H, Greenhill L: Methylphenidate treatment of hyperactive autistic children. J AmAcad Child Adolesc Psychiatry 27:248-251, 1988.

Bouvard MP, Leboyer M, Launay J, Recasens C, Plumet M, Waller-Perotte D, Tabuteau F, Bondoux D, Dugas M, Lensing P, Panksepp J: Low-dose naltrexone effects on plasma chemistries and clinical symptoms in autism: A double-blind, placebo-controlled study. Psychiatry Res 58:191-201, 1995.

Brede M, Nagy G, Philipp M, Sorensen JB, Lohse MJ, Hein L: Differential control of adrenal and sympathetic catecholamine release by alpha 2-adrenoceptor subtypes. Mol Endocrinol 17:1640-1646, 2003.

Burgess JR, Stevens L, Zhang W and Peck L: Long-chain polyunsaturated fatty acids in children with attention-deficit hyperactivity disorder. Am J Clin Nutr 71:327S-330S, 2000.

Campbell M, Anderson LT, Small AM, Adams P, Gonzalez NM, Ernst M: Naltrexone in autistic children: Behavioral symptoms and attentional learning. J Am Acad Child Adolesc Psychiatry 32:1283-1291, 1993.

Carey T, Ratliff-Schaub K, Funk J, Weinle C, Myers M, Jenks J: Double-blind placebo-controlled trial of secretin: Effects on aberrant behavior in children with autism. J Autism Dev Disord 32:161-167, 2002.

Cazzullo AG, Musetti MC, Musetti L, Bajo S, Sacerdote P, Panerai A: Beta-endorphin levels in peripheral blood mononuclear cells and long-term naltrexone treatment in autistic children. European Neuropsychopharmacol 9:361-366, 1999.

Chakrabarti S, Fombonne E: Pervasive developmental disorders in preschool children. JAMA 285:3093-3099, 2001.

Connor DF, Fletcher KE, Swanson JM: A meta-analysis of clonidine for symptoms of attention-deficit hyperactivity disorder. J Am Acad Child Adolesc Psychiatry 38:1551-1559, 1999.

Cook EH, Leventhal BL, Heller W, Doe A, Doe B: Autistic children and their first-degree relatives: Relationships between serotonin and norepinephrine levels and intelligence. J Neuropsychiatry Clin Neurosci 2:268-274, 1990.

Couturier JL, Nicolson R: A retrospective assessment of citalopram in children and adolescents with pervasive developmental disorders. J Child Adolesc Psychopharmacol 12:243-248, 2002.

Czapinski P, Blaszczyk B, Czuczwar SJ: Mechanisms of action of antiepileptic drugs. Curr Top Medicinal Chem 5:3-14, 2005.
Danielsson S, Gillberg IC, Billstedt E, Gillberg C, Olsson I: Epilepsy in young adults with autism: A prospective population-based follow-up study of 120 individuals diagnosed in childhood. Epilepsia 46:918-923, 2005.

Dossenbach M, Erol A, el Mahfoud Kessaci M, Shaheen MO, Sunbol MM, Boland J, Hodge A, O'Halloran RA, Bitter I: Effectiveness of antipsychotic treatments for schizophrenia: Interim 6-month analysis from a prospective observational study (IC-SOHO) comparing olanzapine, quetiapine, risperidone, and haloperidol. J Clin Psychiatry 65:312-321, 2004.

Elchaar GM, Maisch NM, Augusto LM, Wehring HJ: Efficacy and safety of naltrexone use in pediatric patients with autistic disorder. Ann Pharmacother 40:1086-1095, 2006.

Ernst M, Devi L, Silva RR, Gonzalez NM, Small AM, Malone RP, Campbell M: Plasma beta-endorphin levels, naltrexone, and haloperidol in autistic children. Psychopharmacol Bull 29:221-227, 1993.

Fatemi SH, Realmuto GM, Khan L, Thuras P: Fluoxetine in treatment of adolescent patients with autism: A longitudinal open trial. J Autism Dev Disord 28:303-307, 1998.

Ferrari PF, van Erp AM, Tornatzky W, Miczek KA: Accumbal dopamine and serotonin in anticipation of the next aggressive episode in rats. Eur J Neurosci 17:371-378, 2003.

Findling RL: Pharmacological treatment of behavioral symptoms in autism and pervasive developmental disorders. J Clin Psychiatry 66:26-31, 2005.

Findling RL, Maxwell K, Wiznitzer M: An open clinical trial of risperidone monotherapy in young children with autistic disorder. Psychopharmacol Bull 33:155159, 1997.

Findling RL, McNamara NK, Gracious BL, O'Riordan MA, Reed MD, Demeter C, Blumer JL: Quetiapine in nine youths with autistic disorder. J Child Adolesc Psychopharmacol 14:287-294, 2004.

Food and Drug Administration: FDA Approves the First Drug to Treat Irritability Associated with Autism, Risperdal. FDA News, 2006.

Gilberg C. Endogenous opioids and opiate antagonists in autism: Brief review of empirical findings and implications for clinicians. Dev Med Child Neurol 37:237-245, 1995.

Gobbi G, Gaudreau PO, Leblanc N: Efficacy of topiramate, valproate, and their combination on aggression/agitation behavior in patients with psychosis. J Clin Psychopharmacol 26:467-473, 2006.

Greenhill LL, Swanson JM, Vitiello B, Davies M, Clevenger $\mathrm{W}, \mathrm{Wu} \mathrm{M}$, Arnold LE, Abikoff $\mathrm{HB}$, Bukstein OG, Conners CK, Elliott GR, Hechtman L, Hinshaw SP, Hoza B, Jensen PS, Kraemer HC, March JS, Newcorn JH, Severe JB, Wells K, Wigal T: Impairment and deportment responses to different methylphenidate doses in children with ADHD: The MTA titration trial. J Am Acad Child Adolesc Psychiatry 40:180-187, 2001.

Haddad PM and Wieck A: Antipsychotic-induced hyperprolactinaemia: Mechanisms, clinical features and management. Drugs 64:2291-2314, 2004. 
Halperin JM, Kalmar JH, Schulz KP, Marks DJ, Sharma V, Newcom JH: Elevated childhood serotonergic function protects against adolescent aggression in disruptive boys. J Am Acad Child Adolesc Psychiatry 45:833-840, 2006.

Handen BL, Feldman H, Gosling A, Breaux AM, McAuliffe S: Adverse side effects of Ritalin among mentallyretarded children with ADHD. J Am Acad Child Adolesc Psychiatry 30:241-245, 1991.

Handen BL, Johnson CR, Lubetsky M: Efficacy of methylphenidate among children with autism and symptoms of attention-deficit hyperactivity disorder. J Autism Dev Disord 30:245-255, 2000.

Hanley HG, Stahl SM, Freedman DX, Doe A, Doe B: Hyperserotonemia and amine metabolites in autistic and retarded children. Arch Gen Psychiatry 34:521-531, 1977.

Harris JC: Resolved: Autistic children should have a trial of naltrexone. J Am Acad Child Adolesc Psychiatry 35:248-251, 1996.

Hazell PL, Stuart JE: A randomized controlled trial of clonidine added to psychostimulant medication for hyperactive and aggressive children. J Am Acad Child Adolesc Psychiatry 42:886-894, 2003.

Hellings JA, Nickel EJ, Weckbaugh M, McCarter K, Mosier M, Schroeder SR: The Overt Aggression Scale for rating aggression in outpatient youth with autistic disorder: Preliminary findings. The J Neuropsychiatry Clin Neuroscis 17:29-35, 2005a.

Hellings JA, Weckbaugh M, Nickel EJ, Cain SE, Zarcone JR, Reese RM, Hall S, Ermer DJ, Tsai LY, Schroeder SR, Cook EH: A double-blind, placebo-controlled study of valproate for aggression in youth with pervasive developmental disorders. J Child Adolesc Psychopharmacol 15:682-692, 2005b.

Hellings JA, Zarcone JR, Valdovinos MG, Reese RM, Gaughan E, Schroeder SR: Risperidone-induced prolactin elevation in a prospective study of children, adolescents, and adults with mental retardation and pervasive developmental disorders. J Child Adolesc Psychopharmacol 15:885-892, 2005c.

Hoglund E, Korzan WJ, Watt MJ, Forster GL, Summers TR, Johannessen HF, Renner KJ, Summers CH: Effects of L-DOPA on aggressive behavior and central monoaminergic activity in the lizard Anolis carolinensis, using a new method for drug delivery. Behav Brain Res 156:53-64, 2005.

Hollander E, Dolgoff-Kaspar R, Cartwright C, Rawitt R, Novotny S: An open trial of divalproex sodium in autism spectrum disorders. J Clin Psychiatry 62:530 $534,2001$.

Hollander E, Phillips A, Chaplin W, Zagursky K, Novotny $\mathrm{S}$, Wasserman S, Iyengar R: A placebo controlled crossover trial of liquid fluoxetine on repetitive behaviors in childhood and adolescent autism. Neuropsychopharmacol 30:582-589, 2005 .

Hollander E, Phillips A, King BH, Guthrie D, Aman MG, Law P, Owley T and Robinson R: Impact of recent findings on study design of future autism clinical trials. CNS Spectr 9: 49-56, 2004.
Hollander E, Phillips AT and Yeh C: Targeted treatments for symptom domains in child and adolescent autism. Lancet 362:732-734, 2003a.

Hollander E, Tracy KA, Swann AC, Coccaro EF, McElroy SL, Wozniak P, Sommerville KW, Nemeroff CB: Divalproex in the treatment of impulsive aggression: Efficacy in cluster B personality disorders. Neuropsychopharmacol 28:1186-1197, 2003b.

Hollander E, Swann AC, Coccaro EF, Jiang P, Smith TB: Impact of trait impulsivity and state aggression on divalproex versus placebo response in borderline personality disorder. Am J Psychiatry 162:621-624, 2005b.

Horvath K, Perman JA: Autism and gastrointestinal symptoms. Current Gastroenterol Rep 4:251-258, 2002.

Horvath K, Stefanatos G, Sokoslski KN, Wachtel R, Nabors L, Tildon JT: Improved social and language skills after secretin administration in patients with autistic spectrum disorders. J Assoc Acad Minority Physicians 9:9-15, 1998.

Hoshino Y, Kumashiro H, Kanero M, Takahashi Y: The effects of methylphenidate in early infantile autism and its relation to serum serotonin levels. Folia Psyciatrica et Neurologica Japonica 31:605-614, 1977.

Ihalainen JA, Tanila H: In vivo regulation of dopamine and noradrenaline release by alpha2A-adrenoceptors in the mouse nucleus accumbens. J Neurochem 91:49-56, 2004.

Imamura M, Lee KY, Song Y, Moriyasu M, Chang TM, Chey WY: Role of secretin in negative feedback regulation of postprandial pancreatic secretion in dogs. Gastroenterology 105:548-553, 1993.

Jaselskis CA, Cook EH, Fletcher KE, Leventhal BL: Clonidine treatment of hyperactive and impulsive children with autistic disorder. J Clin Psychopharmacol 12:322-327, 1992.

Johansson AK, Bergvall AH, Hansen S: Behavioral disinhibition following basal forebrain excitotoxin lesions: Alcohol consumption, defensive aggression, impulsivity, and serotonin levels. Behav Brain Res 102:17-29, 1999.

Kemner C, Willemsen-Swinkels SH, DeJonge M, Tuynman-Qua J, vanEngeland H: Open-label study of olanzapine in children with pervasive developmental disorder. J Clin Psychopharmacol 22:455-460, 2002.

Kern JK, Miller VS, Evans PA, Trivedi MH: Efficacy of porcine secretin in children with autism and pervasive developmental disorder. J Autism Dev Disord 32:153-160, 2002.

King BH: Pharmacological treatment of mood disturbances, aggression, and self-injury in persons with pervasive developmental disorders. J Autism Dev Disord 30:439-445, 2000.

Kolevzon A, Mathewson KA, Hollander E: Selective serotonin reuptake inhibitors in autism: A review of efficacy and tolerability. J Clin Psychiatry 67:407-414, 2006.

Leboyer M, Philippe A, Bouvard M, Doe A, Doe B: Whole blood serotonin and plasma beta-endorphin in autistic probands and their first-deree relatives. Biol Psychiatry 45:158-163, 1999. 
Leckman JF, Hardin MT, Riddle MA, Stevenson J, Ort SI, Cohen DJ: Clonidine treatment of Gilles de la Tourette's syndrome. Arch Gen Psychiatry 48:324-328, 1991.

Leventhal BL, Cook EH, Morford M, Doe A, Doe B: Relationships of whole blood serotonin and plasma norepinephrine within families. J Autism Dev Disord 20:499-511, 1990.

MacDonell LE, Skinner FK, Ward PE, Glen AI, Glen AC, Macdonald DJ, Boyle RM, Horrobin DF: Increased levels of cytosolic phospholipase A2 in dyslexics. Prostaglandins Leukot Essent Fatty Acids 63:37-39, 2000.

Mackin P, Watkinson HM, Young AH: Prevalence of obesity, glucose homeostasis disorders and metabolic syndrome in psychiatric patients taking typical or atypical antipsychotic drugs: A cross-sectional study. Diabetologia 48:215-221, 2005.

Malone RP, Maislin G, Choudhury MS, Gifford C, Delaney MA: Risperidone treatment in children and adolescents with autism: Short- and long-term safety and effectiveness. J Am Acad Child Adolesc Psychiatry 41:140-147, 2002.

Malone RP, Gratz SS, Delaney MA, Hyman SB: Advances in drug treatments for children and adolescents with autism and other pervasive developmental disorders. CNS Drugs 19: 923-934, 2005.

Martin A, Koenig K, Scahill L, Bregman J: Open-label quetiapine in the treatment of children and adolescents with autistic disorder. J Child Adolesc Psychopharmacol 9:99-107, 1999.

Martin A, Koenig K, Anderson GM, Scahill L: Low-dose fluvoxamine treatment of children and adolescents with pervasive developmental disorders: A prospective, open-label study. J Autism Dev Disord 33:77-85, 2003.

Masi G, Cosenza A, Mucci M, Brovedani P: A 3-year naturalistic study of 53 preschool children with pervasive developmental disorders treated with risperidone. J Clin Psychiatry 64:1039-1047, 2003.

McDougle CJ, Naylor ST, Cohen DJ, Aghajanian GK, Heninger GR, Price LH: Effects of tryptophan depletion in drug-free adults with autistic disorder. Arch Gen Psychiatry 53:993-1000, 1996a.

McDougle CJ, Naylor ST, Cohen DJ, Volkmar FR, Heninger GR, Price LH: A double-blind, placebo-controlled study of fluvoxamine in adults with autistic disorder. Arch Gen Psychiatry 53:1001-1008, 1996b.

McDougle CJ, Stigler KA, Posey DJ: Treatment of aggression in children and adolescents with autism and conduct disorder. J Clin Psychiatry 64:16-25, 2003.

Mitchell EA, Aman MG, Turbott SH, Manku M: Clinical characteristics and serum essential fatty acid levels in hyperactive children. Clin Pediatr (Phila) 26:406-411, 1987.

Molina V, Ciesielski L, Gobaille S, Mandel P: Effects of the potentiation of the GABAergic neurotransmission in the olfactory bulbs on mouse-killing behavior. Pharmacol Biochem Behav 24:657-664, 1986.

Molloy CA, Manning-Courtney P, Swayne S, Bean J, Brown JM, Murray DS, Kinsman AM, Brasington M, Ulrich CD: Lack of benefit of intravenous synthetic hu- man secretin in the treatment of autism. J Autism Dev Disord 32:545-551, 2002.

Namerow LB, Thomas P, Bostic JQ, Prince J, Monuteaux MC: Use of citalopram in pervasive developmental disorders. Devel Behav Pediatr 24:104-108, 2003.

Niederhofer H, Staffen W, Mair A: Tianeptine: A novel strategy of psychopharmacological treatment of children with autistic disorder. Human Psychopharmacol 18:389-393, 2003.

Owley T, McMahon W, Cook EH, Laulhere T, South M, Mays LZ, Shernoff ES, Lainhart J, Modahl CB, Corsello C, Ozonoff S, Risi S, Lord C, Leventhal BL, Filipek PA: Multisite, double-blind, placebo-controlled trial of porcine secretin in autism. J Am Acad Child Adolesc Psychiatry 40:1293-1299, 2001.

Owley T, Walton L, Salt F, Guter SJ, Winnega M, Leventhal BL, Cook EH: An open-label trial of escitalopram in pervasive developmental disorders. J AmAcad Child Adolesc Psychiatry 44:343-348, 2005.

Patel NC, Crismon ML, Hoagwood K, Jensen PS: Unanswered questions regarding atypical antipsychotic use in aggressive children and adolescents. J Child Adolesc Psychopharmacol 15:270-284, 2005.

Physicians' Desk Reference. Montvale (New Jersey), Thomson Healthcare, 2006.

Posey DJ, Guenin KD, Kohn AE, Swiezy NB, McDougle CJ: A naturalistic open-label study of mirtazapine in autistic and other pervasive developmental disorders. J Child Adolesc Psychopharmacol 11:267-277, 2001.

Potenza MN, Holmes JP, Kanes SJ, McDougle CJ: Olanzapine treatment of children, adolescents, and adults with pervasive developmental disorders: An open-label pilot study. J Clin Psychopharmacol 19:37-44, 1999.

Quintana H, Birmaher B, Stedge D, Lennon S, Freed J, Bridge J, Greenhill L: Use of methylphenidate in the treatment of children with autistic disorder. J Autism Dev Disord 25:283-294, 1995.

Rappaport N, Thomas C: Recent reseach findings on aggressive and violent behavior in youth: Implications for clinical assessment and intervention. J Adolesc Health 35:260-277, 2004.

Ratey JJ, Mikkelsen EH, Smith GB, Upadhyaya A, Zuckerman HS, Martell D, Sorgi P, Polakoff S, Bemporad J: Beta-blockers in the severely and profoundly mentally retarded. J Clin Psychopharmacol 6:103-107, 1986.

Remington G, Sloman L, Konstantareas M, Parker K, Gow $\mathrm{R}$ : Clomipramine versus haloperidol in the treatment of autistic disorder: A double-blind, placebo-controlled, crossover study. J Clin Psychopharmacol 21: 440-444, 2001.

Retz W, Rosler M, Supprian T, Retz-Junginger P, Thome J: Dopamine D3 receptor gene polymorphism and violent behavior: relation to impulsiveness and ADHD-related psychopathology. J Neural Transm 110:561-572, 2003.

Ritvo ER, Yuwiler A, Geller E, Doe A, Doe B: Increased blood serotonin and platelets in early infantile autism. Arch Gen Psychiatry 23:566-572, 1970.

Rothenberger A: Psychopharmacological treatment of self-injurious behavior in individuals with autism. Acta Paedopsychiatrica 56:99-104, 1993. 
RUPP: Risperidone in children with autism and serious behavioral problems. N Engl J Med 347:314-321, 2002.

RUPP: Randomized, controlled, crossover trial of methylphenidate in pervasive developmental disorders with hyperactivity. Arch Gen Psychiatry 62:12661274, 2005a.

RUPP: Risperidone treatment of autistic disorder: Longerterm benefits and blinded discontinuation after 6 months. Amer J Psychiatry 162:1361-1369, 2005b.

Sandman CA: B-endorphin disregulation in autistic and self-injurious behavior: A neurodevelopmental hypothesis. Synapse 2:193-199, 1988.

Sandman CA, Hetrick W, Taylor DV and Chicz-DeMet A: Dissociation of POMC peptides after self-injury predicts responses to centrally acting opiate blockers. Am J Ment Retard 102:182-199, 1997.

Sandman CA, Hetrick W, Taylor D and Marion S: Uncoupling of proopiomelanocortin (POMC) fragments is related to self-injury. Peptides 21:785-791, 2000.

Sandyk R and Bamford CR: Deregulation of hypothalamic dopamine and opioid activity and the pathophysiology of self-mutilatory behavior in Tourette's syndrome. J Clin Psychopharmacol 7:367, 1987.

Schain RJ and Freedman DX: Studies on 5-hydroxyindole metabolism in autistic and other mentally retarded children. J Pediatr 58:315-320, 1961.

Schooler N, Rabinowitz J, Davidson M, Emsley R, Harvey PD, Kopala L, McGorry PD, Van Hove I, Eerdekens M, Swyzen W, De Smedt G: Risperidone and haloperidol in first-episode psychosis: A long-term randomized trial. Am J Psychiatry 162:947-953, 2005.

Shea S, Turgay A, Carroll A, Schulz M, Orlik H, Smith I, Dunbar F: Risperidone in the treatment of disruptive behavioral symptoms in children with autistic and other pervasive developmental disorders. Pediatr 114:e634-e641, 2004.

Sival RC, Duivenvoorden HJ, Jansen PA, Haffmans PM, Duursma SA, Eikelenboom P: Sodium valproate in aggressive behaviour in dementia: A twelve-week open label follow-up study. Int J Geriatr Psychiatry 19: 305312, 2004.

Soderpalm B: Anticonvulsants: Aspects of their mechanism of action. Eur J Pain 6 (Suppl A): 3-9, 2002.

Steingard R, Biederman J, Spencer T, Wilens T, Gonzalez A: Comparison of clonidine response in the treatment of attention-deficit hyperactivity disorder with and without comorbid tic disorders. J Am Acad Child Adolesc Psychiatry 32:350-353, 1993.

Stevens LJ, Zentall SS, Deck JL, Abate ML, Watkins BA, Lipp SR, Burgess JR: Essential fatty acid metabolism in boys with attention-deficit hyperactivity disorder. Am J Clin Nutr 62:761-768, 1995.

Stevens LJ, Zentall SS, Abate ML, Kuczek T, Burgess JR: Omega-3 fatty acids in boys with behavior, learning, and health problems. Physiol Behav 59:915-920, 1996.

Stockton ME, Rasmussen K: Electrophysiological effects of olanzapine, a novel atypical antipsychotic, on A9 and A10 dopamine neurons. Neuropsychopharmacol 14:97-105, 1996.

Stodgell CJ, Loupe PS, Schroeder SR, Tessel RE: Crosssensitization between footshock stress and apomor- phine on self-injurious behavior and neostriatal catecholamines in a rat model of Lesch-Nyhan syndrome. Brain Res 783:10-18, 1998.

Strayhorn JM, Rapp N, Donina W, Strain PS: Randomized trial of methylphenidate for an autistic child. J Amer Acad Child Adolesc Psychiatry 27:244-247, 1988.

Sweetman S (ed.): Martindale: The Complete Drug Reference. London (UK), Pharmaceutical Press, 2004.

Takahashi S, Kanai H, Miyamoto Y, Doe A, Doe B: Reassessment of elevated serotonin levels in blood platelets in early infantile autism. J Autism Childhood Schizophrenia 6:317-326, 1976.

Toichi M, Kamio Y: Paradoxical autonomic response to mental tasks in autism. J Autism Dev Disord 33:417426, 2003.

Troost PW, Lahuis BF, Steenhuis M, Ketelaars CE, Buitelaar JK, VanEngeland H, Scahill L, Minderaa RB, Hoekstra PJ: Long-term effects of risperidone in children with autism spectrum disorders: A placebo discontinuation study. J Am Acad Child Adolesc Psychiatry 44:1137-1144, 2005.

Unis AS, Munson JA, Rogers SJ, Goldson E, Osterling J, Gabriels R, Abbott RD, Dawson G: A randomized, double-blind, placebo-controlled trial of porcine versus synthetic secretin for reducing symptoms of autism. J Am Acad Child Adolesc Psychiatry 41:1315-1321, 2002.

Vancassel S, Durand G, Barthelemy C, Lejeune B, Martineau J, Guilloteau D, Andres C, Chalon S: Plasma fatty acid levels in autistic children. Prostaglandins Leukot Essent Fatty Acids 65:1-7, 2001.

Vergnes M, Depaulis A, Boehrer A, Kempf E: Selective increase of offensive behavior in the rat following intrahypothalamic 5,7-DHT-induced serotonin depletion. Behav Brain Res 29:85-91, 1988.

Wasserman S, Iyengar R, Chaplin WF, Watner D, Waldoks SE, Anagnostou E, Soorya L, Hollander E: Levetiracetam versus placebo in childhood and adolescent autism: A double-blind placebo-controlled study. Int Clin Psychopharmacol 21:363-367, 2006.

Willemsen-Swinkels SH, Buitelaar JK, vanEngeland $\mathrm{H}$ : The effects of chronic naltrexone treatment in young autistic children: A double-blind placebo-controlled study. Biol Psychiatry 39:1023-1031, 1996.

Willemsen-Swinkels SH, Buitelaar JK, Weijnen FG and vanEngeland $\mathrm{H}$ : Placebo-controlled acute dosage naltrexone study in young autistic children. Psychiatry Res 58:203-215, 1995.

Zingarelli G, Ellman G, Hom A, Wymore M, Heidorn S, Chicz-DeMet A: Clinical effects of naltrexone on autistic behavior. Amer J Ment Retard 97:57-63, 1992.

Address reprint requests to: Alexander Kolevzon, M.D. Mount Sinai School of Medicine Department of Psychiatry One Gustave L.Levy Place, Box 1230 New York, NY 10029

E-mail: alexander.kolevzon@mssm.edu 